\title{
Charles Duclos, Considérations sur les mœurs des ce siècle
}

\section{Franco Piva}

\section{(2) OpenEdition}

1 Journals

\section{Edizione digitale}

URL: https://journals.openedition.org/studifrancesi/26351

DOI: 10.4000/studifrancesi.26351

ISSN: 2421-5856

\section{Editore}

Rosenberg \& Sellier

\section{Edizione cartacea}

Data di pubblicazione: 1 avril 2007

Paginazione: 181-182

ISSN: 0039-2944

\section{Notizia bibliografica digitale}

Franco Piva, «Charles Duclos, Considérations sur les mœurs des ce siècle», Studi Francesi [Online], 151

(LI | I) | 2007, online dal 30 novembre 2015, consultato il 23 novembre 2021. URL: http://

journals.openedition.org/studifrancesi/26351 ; DOI: https://doi.org/10.4000/studifrancesi.26351

Questo documento è stato generato automaticamente il 23 novembre 2021.

\section{(c) (i) (9)}

Studi Francesi è distribuita con Licenza Creative Commons Attribuzione - Non commerciale - Non opere derivate 4.0 Internazionale. 


\title{
Charles Duclos, Considérations sur les mœurs des ce siècle
}

\author{
Franco Piva
}

\section{NOTIZIA}

CHARLES DUCLOS, Considérations sur les mouurs des ce siècle. Edition critique avec

introduction et notes par Carole DORNIER, Paris, Honoré Champion, 2005, pp. 267.

1 Accolte con parecchie riserve al loro primo apparire nel 1751, le Considérations finirono con l'essere per i contemporanei e per coloro che le lessero negli anni che seguirono la morte del loro autore che, nel frattempo, le aveva riviste e corrette, il maggiore titolo di gloria di Charles Duclos, prima di cadere, come la restante opera del segretario dell'Académie-Française, in un oblio dal quale solo di recente hanno iniziato a trarle, in opere tuttavia di carattere generale, alcuni storici delle idee quali Mauzi, Walter e Gaulin. Offuscate da opere quali le Confessions du comte de ${ }^{* * *}$ o i Mémoires pour servir à l'histoire des mœurs $d u \mathrm{XVIII}^{\mathrm{e}}$ siècle, con i quali sono state spesso confuse, le Considérations meritavano, in realtà, di essere riproposte nella loro integralità, ed in un testo filologicamente accurato, all'attenzione di quanti abbiano intenzione di conoscere meglio non solo Duclos, un autore ancora troppo poco e troppo mal conosciuto, ma anche il secolo di cui l'autore delle Considérations in particolare è stato un osservatore lucido ed attento, oltre che un protagonista. Considerate per lo più come un'opera di moralista e lette nella prospettiva di opere quali i Caractères di La Bruyère, ai quali devono certamente molto ma coi quali non possono, né devono essere confuse, le Considérations appartengono di fatto ad un altro filone letterario e si propongono altri obiettivi, che Carole Dornier ha posto molto chiaramente in evidenza nella lunga «Introduction» (pp. 1-64) che precede le Considérations stesse, date nel testo dell'edizione del 1767, l'ultima sicuramente curata dall'Autore, e che sono altrettanto lucidamente riassunti nella quarta di copertina. «C'est par un malentendu que l'ouvrage est lu comme un recueil de moraliste, alors qu'il rompt avec la perspective universaliste et atemporelle de la maxime, avec une écriture fragmentaire qui vise au 
seul démas-quage des faux-semblants. Machine de guerre contre les valeurs de la société aristocratique, support de la promotion d'une morale de l'utile, qui tente de s'imposer contre la culture de l'homme de cour, les Considérations appartiennent à un courant de pensée longtemps négligé dans la tradition française. Après les projets de l'abbé de Saint-Pierre, avant De l'Esprit d'Helvétius, le livre de Duclos tente de promouvoir des critères d'évaluation des conduites et des institutions: bonheur du plus grand nombre, utilité et bien public. C'est la mondanité qui devient alors la cible de ses critiques, comme culture et fonctionnement social marqués par les intérêts particuliers, la futilité, la tyrannie des modes et de la crainte du ridicule. Duclos revendique, pour des groupes sociaux en quête de légitimité, de nouvelles sources de domination symbolique, de nouvelles formes de reconnaissance: il faut fixer «le prix des choses»"».

Opera di «combat» assai più che disincantata riflessione di moralista, le Considérations aiuteranno a capire meglio, e a rivalutare, non solo Duclos, degno rappresentante, nella sua complessità e nella contraddittorietà stessa di alcune sue prese di posizione, di un secolo che, semplificando troppo, è stato chiamato dei Lumi, ma anche quelle opere, di una narrativa apparentemente leggera se non banale, quali le sopraricordate Confessions $d u$ comte $d e^{* * *}$, per le quali Duclos è, oggi, sopratutto conosciuto. 